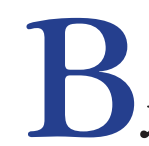

лияние наружной противовоспалительной терапии на морфофункциональные характеристики эпидермального барьера. Оптимизация схем лечения атопического дерматита

Круглова Л. С. ${ }^{1}$, Петрунин Д. Д.,**

1 Центральная государственная медицинская академия Управления делами Президента Российской Федерации 121359, Российская Федерация, г. Москва, ул. Маршала Тимошенко, д. 19, строение 1 А

2000 «ЛЕО Фармасьютикал Продактс»

125315, Российская Федерация, г. Москва, Ленинградский пр-т, д. 72, корп. 2

В данном обзоре литературы анализируются накопленные экспериментальные данные о влиянии на морфрофрункциональные характеристики эпидермального барьера наружной терапии топическими глюкокортикостероидами (ТГКС) и мазью такролимуса. Если ТГКС обладают выраженным отрицательным влиянием практически на все параметры эпидермального барьера, включая структуру и толщину эпидермиса, целостность рогового слоя, плотность соединения корнеоцитов, протеазную активность, показатели увлажненности, pH, диффреренцировки, структуру липидных пластин и т. д., то мазь такролимуса (Протопик ${ }^{\circledR}$ ) оказывает положительное действие на большинство указанных параметров, позволяя компенсировать негативное влияние ТГКС.

Эти сведения позволяют сфрормулировать рекомендации по оптимизации наружной терапии атопического дерматита с поэтапным переходом с ТГКС на мазь Протопик ${ }^{\circledast}$.

Ключевые слова: эпидермальный барьер, атопический дерматит, такролимус, топические глюкокортикостероиды, наружная терапия, Протопик

Конорликт интересов: Круглова Л. С. оказывала консультационные услуги и выступала докладчиком для ООО «ЛЕО Фармасьютикал Продактс»; Петрунин Д. Д. является сотрудником ООО «ЛЕО Фармасьютикал Продактс».

Для цитирования: Круглова Л. С., Петрунин Д. Д. Влияние наружной противовоспалительной терапии на морфофрункциональные характеристики эпидермального барьера. Оптимизация схем лечения атопического дерматита. Вестник дерматологии и венерологии. 2018;94(4):73-82. https://doi.org/10.25208/0042-4609-2018-944-73-82 


\section{I \\ mpact of topical anti-inflammatory therapy on morpho-functional characteristics of epidermal barrier. Optimization of atopic dermatitis treatment schedules}

Larisa S. Kruglova ${ }^{1}$, Dmitry D. Petrunin²,*

${ }^{1}$ Central State Medical Academy of Affairs Management Department of President of Russian Federation Marshala Timoshenko str., 19, building 1A, Moscow, 121359, Russian Federation

${ }^{2}$ LEO Pharmaceutical Products, LLC

Leningradsky prospect, 72, korpus 2, Moscow, 125315, Russian Federation

In this literature review data regarding impact of topical therapy with topical corticosteroids (TCS) and tacrolimus ointment on morpho-functional characteristics of epidermal barrier is analyzed. Whereas TCS has profound negative impact on nearly all epidermal barrier parameters, including epidermal structure and thickness, integrity and cohesion of stratum corneum, protease activity, hydration, $\mathrm{pH}$, differentiation, lipid lamellae structure etc., tacrolimus ointment (Protopic ${ }^{\circledR}$ ) exerts positive effect on the majority of the aforementioned parameters, thus allowing to compensate deleterious effect of TCS.

These data allow defining recommendations upon optimization of topical therapy of atopic dermatitis with stepwise switching from TCS to Protopic ${ }^{\circledR}$ ointment.

Keywords: epidermal barrier, atopic dermatitis, tacrolimus, topical corticosteroids, topical therapy, Protopic ${ }^{\bullet}$

Conflict of interest: Kruglova L. S. rendered consulting services and acted as a speaker for LLC "LEO Pharmaceutical Products"; Petrunin D. D. is an employee of LLC "LEO Pharmaceutical Products". 
Генетически детерминированные нарушения эпидермального барьера играют важнейшую роль в патогенезе атопического дерматита. Хотя до сих пор не утихает полемика, какое звено в патогенезе АД первично - иммунные нарушения (повышение экспрессии ИЛ-4, 5, 13, 25, 31 и других биологически активных веществ, роль воспалительных дендритных клеток эпидермиса и т. д.) - концепция «inside-outside» - либо нарушения эпидермального барьера (мутации генов белка фрилаггрина, ингибиторов сериновых протеаз (LEKTI), повышение активности сериновых протеаз - калликреинов 5 и 7, нарушение диффреренцировки кератиноцитов, выраженное нарушение эпидермального липидного гомеостаза и т. д.) - концепция "outside-inside», сегодня большинство авторов склоняется ко второй теории [1-5]. В пользу данной концепции свидетельствуют следующие фракты [5-9].

1. Выраженность нарушений эпидермального барьера коррелирует с тяжестью течения АД.

2. Значительные нарушения эпидермального барьера имеют место как в очагах поражения, так и на непораженной коже больных.

3. При АД доказана эфффективность базовой наружной терапии эмолентами (смягчающими и увлажняющими средствами), позволяющими лишь частично скорректировать нарушения барьерной функции.

При этом первой линией и «золотым стандартном» терапии обострений атопического дерматита являются топические глюкокортикостероиды (ТГКС), что нашло отражение как в российских [10], так и в зарубежных клинических рекомендациях $[11,12]$. Мощный противовоспалительный, иммуносупрессивный и антипролиферативный эффрект ТГКС обусловливает эфрфективность данного класса лекарственных средств у большинства пациентов с атопическим дерматитом.

В то же время хорошо изучено выраженное отрицательное влияние наружной стероидной терапии, особенно при длительном применении, на морфофрункциональные характеристики эпидермального барьера [1, 13]. Активность модифицированных синтетических ТГКС во много раз превышает активность глюкокортикостероидов, синтезируемых в организме человека [14], а потому и их воздействие на эпидермальный барьер может быть гораздо более разрушительным. В частности, было продемонстрировано, что даже краткий курс сильных топических ГКС приводит к выраженным нарушениям эпидермального барьера [13].

Kaо J. S. и соавт. [13] установили, что применение 0,05 \% клобетазола пропионата дважды в день в течение всего трех дней приводит к выраженному (на 70 \%) замедлению регенерации эпидермиса по сравнению с нормой, снижению продукции и секреции ламеллярных телец и уменьшению содержания липидов в межклеточном пространстве рогового слоя. При этом указанные нарушения барьерной функции и структурной целостности рогового слоя поддавались коррекции путем наружного применения смеси физиологических липидов (церамиды, холестерин, СЖК) в эквимолярном соотношении [13]; это указывает, что описанные негативные изменения являются следствием подавляющего действия ТГКС на выработку эпидермальных липидов.

В исследовании Kolbe L. и соавт. [15] при помощи различных неинвазивных методик изучалось влияние на эпидермальный барьер наружной терапии 0,05 \% кремом клобетазола пропионата, наносившимся дважды в день на кожу предплечий 24 здоровых добровольцев женского пола в течение 3-4 недель. Было установлено, что применение клобетазола пропионата привело к значительному уменьшению толщины рогового слоя, размера клеток зернистого слоя (с $572 \pm 89$ до

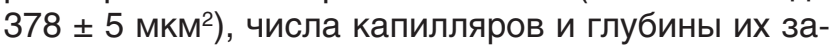
легания (в контрольной группе глубина составила $68 \pm 9$ мкм, в группе, подвергшейся воздействию клобетазола, $-59 \pm 12$ мкм), очень выраженному истончению дермы по данным УЗИ ( $p<0,001$ по сравнению с исходным; причем наиболее выраженное уменьшение толщины дермы имело место в первую неделю применения ТГКС), а также значительному снижению всех липидных фракций эпидермиса (см. табл. 1).

Sheu H. М. и соавт. [16] провели исследование с участием 10 пациентов с атрофией кожи лица, вызванной терапией наружными стероидами. Все они длительно применяли различные ТГКС (в среднем 15 месяцев) и имели характерные проявления атрофии эпидермиса - истонченная кожа с блестящей поверхностью, утрата кожного рисунка, дифрфузная эритема, телеангиоэктазии и т. д. Авторы провели сравнительный анализ биоптатов из очагов поражения и участков здоровой кожи

Таблица 1. Влияние наружной терапии 0,05 \% клобетазола пропионатом на содержание липидов в роговом слое эпидермиса здоровых добровольцев

Table 1. The effect of external therapy with $0.05 \%$ clobetasol propionate on the lipid content in the stratum corneum of healthy volunteers

\begin{tabular}{ccccccccc}
\hline Класс липидов* & Церамид 7 & Церамид 6 & Церамид 5 & Церамид 4 & Церамид 3 & Церамид 1 & Стеролы & СЖК \\
\hline $\begin{array}{c}\text { Уменьшение по сравнению } \\
\text { с исходным (\%), среднее } \pm \text { С0 }\end{array}$ & $29 \pm 11$ & $20 \pm 9$ & $38 \pm 7$ & $15 \pm 7$ & $35 \pm 6$ & $37 \pm 5$ & $30 \pm 20$ & $24 \pm 14$ \\
\hline
\end{tabular}

Примечания: По данным Kolbe L и соавт. [15]. * Содержание церамида 2 в данном эксперименте не удалось определить по техническим причинам.

Notes: According to Kolbe L. et al. [15]. * The content of ceramide 2 in this experiment could not be determined for technical reasons. 
(контроль) с помощью световой и электронной микроскопии, включая изучение криостатных срезов (срезы эпидермиса, подвергнувшиеся заморозке при сверхнизкой температуре с тетраоксидом рутения), а также показатели трансэпидермальной потери воды (ТЭПВ). Полученные результаты достаточно наглядны - число слоев рогового слоя кожи, подвергшейся воздействию ТГКС, составило 9,4 $\pm 1,3$, контрольных образцов $-18,0 \pm 1,2$ $(p<0,001)$, в опытных образцах также наблюдалось резкое снижение содержания и образования кератогиалиновых и ламеллярных гранул, содержания липидов (по данным полуколичественной денситометрии, 0,22 $\pm 0,09$ против 1,0 $\pm 0,22, p<$ $0,001)$ и уменьшение количества межклеточных липидных пластин. Эти изменения сопровождались выраженным повышением: 21,3 \pm 11,8 против 6,7 $\pm 1,29$ г/м². Эти данные свидетельствуют о выраженном негативном влиянии ТГКС на морфофрункциональные характеристики эпидермального липидного барьера.

В еще одном исследовании Haapasaari K. М. и соавт. [17] изучали влияние наружной стероидной терапии на синтез коллагена с учетом содержания аминоконцевых пропептидов проколлагена I (PINP) и III (PIIINP) типа в эпидермисе 14 здоровых добровольцев, в течение одной недели дважды в день наносивших различные мази ТГКС и плацебо (контроль). Было установлено, что через 7 дней применения гидрокортизона и бетаметазона содержание PINP снизилось на 35 и $69 \%$, а PIIINP - на 35 и $62 \%$ соответственно, что говорит о развитии атрофических изменений уже в течение первой недели применения ТГКС.

Применение ТГКС оказывает выраженное негативное влияние на синтез и структуру не только эпидермальных белков и липидов, но и других важных компонентов межклеточного матрикса мукополисахаридов (гликозаминогликанов). Так, в исследовании Gebhardt С. и соавт. [18] после внесения в культуру клеток фрибробластов и НаСаТ кератиноцитов 150 нМ дексаметазона через 24 часа отмечалось выраженное, почти двукратное снижение гиалуронана - ключевого гликозаминогликана человеческой кожи, участвующего в процессах тканевого гомеостаза, пролиферации клеток, гидратации эпидермиса и репарации $(p=$ 0,027 для фрибробластов и $p=0,015$ для кератиноцитов), причем первые признаки снижения отмечались уже через 3 часа. Полученные данные были подтверждены результатами исследования in vivo, в рамках которого 0,1\% мазь дексаметазона наносилась на кожу здоровых добровольцев трижды в день в течение 3 дней, что повлекло резкое снижение гиалуронана в полученных после этого биоптатах.

Эти результаты перекликаются с более ранними исследованиями - например, в исследовании
Zhang W. и соавт. [19] было продемонстрировано, что внесение в культуру фрибробластов дермы $10^{-6}$ дексаметазона приводило к почти полной на 97-98 \% супрессии экспрессии МРНК гиалуронан-синтазы, причем данный эффрект развивался очень быстро - через 1 час после внесения стероида экспрессия HAS2 составляла $28 \%$ от контрольной, а через 2 часа - 1,2\%.

Таким образом, отрицательное влияние ТГКС на эпидермальный барьер не только затрагивает различные структуры кожи, но и отмечается уже в начале применения препаратов, что должно учитываться при назначении терапии.

В одной из работ Saarni H. и соавт. [20] продемонстрировали, что даже в очень низкой концентрации ГКС угнетают синтез гиалуроновой кислоты фрибробластами - в концентрации $10^{-10}$ гидрокортизона бутирата и бетаметазона валерата снижение составило 50 и 95 \% соответственно. При этом отмечено, что для подавления синтеза гиалуроновой кислоты требуются концентрации стероидов в 100-1000 раз меньшие, чем необходимые для ингибирования синтеза коллагена.

Таким образом, наряду с выраженным противовоспалительным и иммуносупрессивным эфффектом, обусловливающим высокую эфрфективность ТГКС в лечении атопического дерматита, применение данного класса лекарственных средств приводит к тяжелым нарушениям эпидермального барьера, который уже глубоко компрометирован у атопиков. В результате происходит замыкание порочного круга - усугубление повреждения эпидермального барьера влечет усиление трансэпидермальной потери воды, более выраженную сухость кожи и облегчение проникновения внешних триггеров АД: аллергенов, ирритантов, инфекционных агентов и т. д., что приводит к трудно контролируемому течению заболевания и более частым обострениям (см. рис. 1).

Эмоленты позволяют отчасти компенсировать отрицательное влияние ТГКС, но, во-первых, смягчающие и увлажняющие средства не в состоянии полностью скорректировать вызванные ТГКС негативные изменения, а во-вторых, эффрект от их применения наблюдается только во время постоянного использования; при прекращении или пропусках в нанесении эмолентов на фроне стероидной терапии дисфункция эпидермального барьера быстро нарастает.

Решением проблемы может быть переход с ТГКС, после уменьшения первичной остроты процесса, на другой класс наружных противовоспалительных средств - топические ингибиторы кальциневрина. В многочисленных клинических исследованиях было продемонстрировано, что наиболее активный представитель данного класса - такролимус (Протопик ${ }^{\circledR}$ мазь) по клинической эфрфективности при лечении атопического 


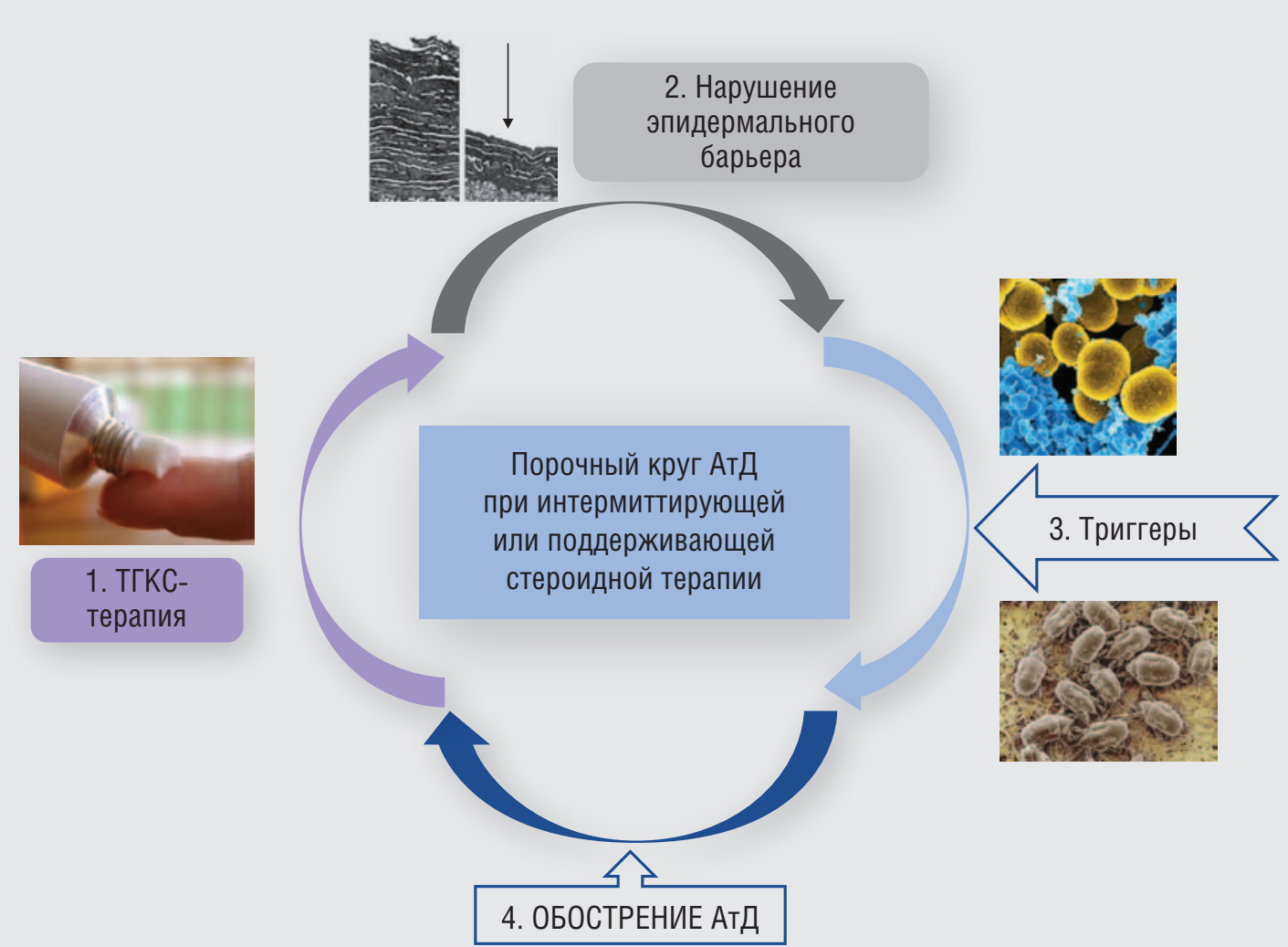

Рис. 1. Порочный круг, наблюдающийся при интермиттирующем или поддерживающем применении ТГКС для купирования обострений и контроля течения атопического дерматита

Fig. 1. A vicious circle observed in the intermittent or supportive application of TGCS for the relief of exacerbations and control of the course of atopic dermatitis

дерматита сопоставим с сильными ТГКС и превосходит ТГКС слабой и умеренной активности [21], при этом оказывая положительный эффект на параметры эпидермального барьера, что отличает его от ТГКС.

Tak, Kyllonen H. и соавт. [22] провели открытое исследование влияния длительной интермиттирующей терапии мазью такролимуса и ТГКС на синтез коллагена и толщину эпидермиса. В исследовании приняли участие 2 группы пациентов, из которых 56 в течение 12 месяцев получали интермиттирующие курсы лечения мазью такролимуса 0,1\%, а 36 - ТГКС ॥-III класса активности по той же схеме. Контрольную группу составили здоровые добровольцы. Исходно и через 12 месяцев лечения у участников определялись уровни пропептидов коллагена I (PINP) и III (PIIINP), а также толщина эпидермиса при помощи УЗИ (DUB20-S; Tabernapro medicum, Люнебург, Германия; 30 МГц, 8 точек). Через 12 месяцев в группе, получавшей лечение мазью такролимуса, толщина эпидермиса увеличилась на 114,7 мкм (+9,0\%, $p<0,001)$, тогда как в группе, получавшей ТГКС, уменьшилась на 110,7 мкм (-8,2 \%, $p<0,001)$ (см. рис. 2). При использовании такролимуса совокупный уровень PINP и PIIINP возрос на 272,0 мкг/л $(+149,9$ \%, $p<$ 0,001); для сравнения, в группе, получавшей ТГКС, этот показатель увеличился лишь на 11,0 мкг/л
(+3,9 \%, статистически не значимо) (см. табл. 2). Эти данные свидетельствуют об отсутствии атрофогенного действия и инициации репаративных процессов в эпидермисе на фоне терапии мазью такролимуса.

Примечательно, что в группе, получавшей лечение Протопиком, были 3 пациента, у которых на фоне длительной предшествующей стероидной терапии имелись признаки атрофии кожи. Через 12 месяцев лечения у всех трех пациентов наблюдалось увеличение синтеза коллагена, толщины кожи и устранение визуальных симптомов атрофии.

Позднее указанные результаты получили подтверждение в исследовании Бакулева А. Л. и соавт. [23]. Под наблюдением находились 60 пациентов с атопическим дерматитом, из которых 22 получали лечение мазью Протопик ${ }^{\circledR} 0,1 \%$ один раз в день в течение 14 дней, а 38 - мазью метилпреднизолона ацепоната по той же схеме. Наряду с клинической оценкой проводилось исследование кожи с помощью цифровой ультразвуковой системы высокого разрешения DUB (TPMGmbH, Германия; 33 МГц, разрешение 78 мкм). Клиническая эффрективность терапии была высокой в обеих группах и не имела статистических различий $(p \geq 0,05)$. Данные УЗИ после лечения у больных, получавших ТГКС и Протопик ${ }^{\circledR}$, имели существенные различия. В частности, снижение абсолютных значений тол- 
150

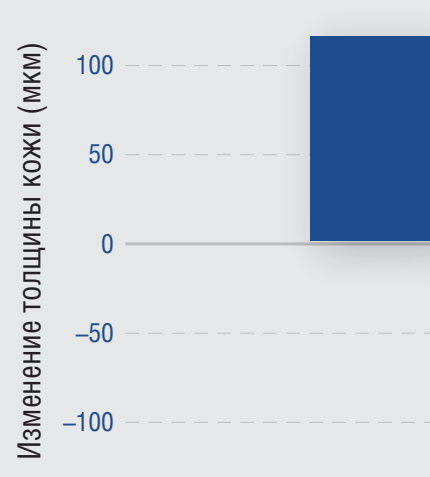

Мазь такролимуса 0,1\% $(n=44)$

$\operatorname{T\Gamma KC}(n=30)$

$-150$

Рис. 2. Влияние длительной (12 месяцев) интермиттирующей терапии мазью такролимуса (Протопик ${ }^{\circledR}$ и ТГКС на толщину кожи

Fig. 2. Effect of long-term (12 months) intermittent therapy with tacrolimus ointment (Protopic ${ }^{\circledR}$ ) and TGCS on skin thickness

Таблица 2. Совокупный уровень пропептидов коллагена PINP и PIIINP, мкг/л

Table 2. The total level of collagen PINP and PIIINP propeptides, $\mu \mathrm{g} / \mathrm{l}$

\begin{tabular}{ccc}
\hline Группа & Исходно & Через 12 месяцев \\
\hline Мазь такролимуса $\left(\right.$ Протопик $\left.{ }^{\circledR}\right)(n=56)$ & 193,0 & $465,0(+149,9 \%, p<0,001)$ \\
\hline ТГКС $(n=36)$ & 285,0 & $296,0(+3,9 \%$, незначимо $)$ \\
\hline Контроль $(n=27)$ & 515,0 & ND \\
\hline
\end{tabular}

щины дермы после лечения метилпреднизолона ацепонатом в сравнении с контрольными значениями $(p<0,001)$, зарегистрированное у данной группы, свидетельствовало о наличии субклинических атросрических процессов в дерме. Применение Протопика характеризовалось ультрасонографрическими признаками нормализации плотности эпидермиса и дермы, что говорит о мощном противовоспалительном действии данного препарата в различных слоях кожи, вовлеченных в патологический процесс; при этом толщина дермы соответствовала контрольным значениям данного показателя и была выше абсолютных цифр, зарегистрированных у лиц, получавших метилпреднизолона ацепонат $(p<0,001)$, что свидетельствует об отсутствии атрофогенного действия такролимуса, характерного для ТГКС, включая препараты умеренной активности (метилпреднизолона ацепонат).

В дальнейшем схожие результаты были получены с использованием конфокальной микроскопии в исследовании Jiráková А. и соавт. [24], в котором приняли участие 45 пациентов с атопическим дерматитом: 1 группа $(n=23)$ в течение трех месяцев один раз в день наружно применяла метилпреднизолона ацепонат, а вторая $(n=22)-$ мазь Протопик ${ }^{\circledR}$ дважды в день в течение того же срока. В группе, получавшей метилпреднизолона ацепонат, отмечалось заметное и статистически значимое снижение толщины эпидермиса, чего не наблюдалось в группе, получавшей такролимус.
Кроме того, в шиповатом слое эпидермиса пациентов из группы, получавшей ТГКС, была увеличена доля кератиноцитов с измененной фрормой.

В исследовании Chittock J. и соавт. [25] 17 добровольцев с атопическим дерматитом в фазу ремиссии в течение 8 недель дважды в неделю наносили 0,1 \% мазь такролимуса и 0,1\% крем бетаметазона валерата на внутреннюю поверхность правого и левого предплечья соответственно. Оцениваемыми параметрами были трансэпидермальная потеря воды, показатели инфракрасной денситометрии, рН поверхности кожи, электрическая емкость и протеазная активность в роговом слое эпидермиса.

После завершения 8-недельного курса проводилась оценка нарастания ТЭПВ при последовательном удалении слоев клеток рогового слоя эпидермиса при помощи липкой ленты (20 повторений). Применение Протопика ${ }^{\circledR}$ приводило к значительно более медленному нарастанию данного показателя: AUC 480,7 г/M²/4 в сравнении с AUC 598,5 г/M²/4 для бетаметазона валерата $(p<0,01)$ и AUC 579,2 г/м²/4 для не подвергавшихся лечению участков кожи, а также значительному снижению ТЭПВ в сравнении с исходным значением ( $p<0,0001)$, что говорит о благоприятном влиянии терапии такролимусом на структуру рогового слоя. ТГКС при применении по данной схеме (2 раза в неделю в течение 8 недель) не оказал значимого влияния на этот параметр. Также бетаметазона валерат оказывал выраженное негативное влия- 
ние на когезию (межклеточные связи) клеток рогового слоя по данным денситометрии. В группе пациентов, применявших Протопик ${ }^{\circledR}$, наблюдалось достоверное повышение электрической емкости эпидермиса и превосходство по данному параметру перед ТГКС $(p<0,05)$ и исходным значением $(p<0,01) ; 43,35 \pm 1,45,40,76 \pm 1,47$ и $37,29 \pm 1,23$ относительных единиц емкости. Терапия ТГКС приводила к значительно большему повышению $\mathrm{pH}$ поверхности кожи в сравнении с такролимусом $(5,34$ и 5,20; $p<0,01)$ и с исходным значением $(5,10$; $p<0,001)$, что снижает активность сфиингомиелиназы и бета-глюкоцереброзидазы (ключевых для биосинтеза церамидов феерментов) и, таким образом, приводит к нарушению структуры межклеточных липидных мембран и, вследствие этого, барьерной фрункции эпидермиса $[1,26,27]$.

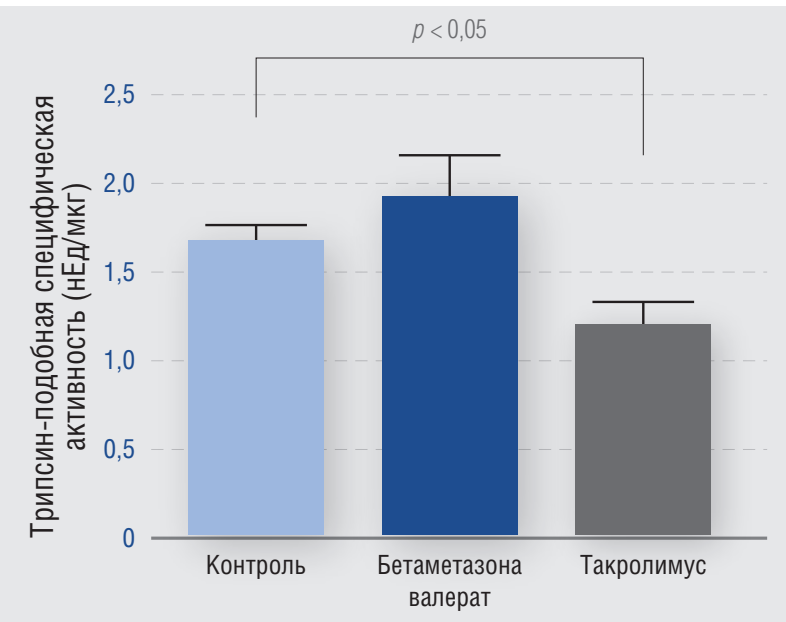

Рис. 3. Влияние 8-недельной терапии 2 раза в неделю мазью такролимуса (Протопик ${ }^{\circledR}$ и и бетаметазона валерата на трипсин-подобную активность в роговом слое

Fig. 3. Effect of 8-week treatment 2 times a week with tacrolimus ointment $\left(\right.$ Protopic $^{\circledR}$ ) and betamethasone valerate on trypsin-like activity in the stratum corneum
Особый интерес представляют данные о протеолитической активности в роговом слое, полученные в данном исследовании. Оценивались химотрипсин-подобная (калликреин-7) и трипсинподобная (калликреины 5 и 14) протеазные активности. Было установлено, что на фоне терапии мазью Протопик ${ }^{\circledR}$ происходило снижение всех трех типов протеолитической активности, причем для казеинолитической и трипсин-подобной это снижение было статистически значимым, тогда как терапия ТГКС сопровождалась тенденцией к повышению данного показателя, что еще раз подчеркивает отрицательное влияние ТГКС на морфоофункциональные показатели эпидермального барьера (см. рис. 3).

Наблюдающееся при АД нарастание активности сериновых протеаз приводит к усилению десквамации корнеоцитов и активации рецепторов второго типа, активируемых протеазами (PAR-2), которые стимулируют диффференцировку кератиноцитов и угнетают секрецию ламеллярных телец, что усугубляет нарушение эпидермального барьера и приводит к повышенной проницаемости эпидермиса для экзогенных триггеров и увеличению ТЭПВ [1, 26, 27].

В исследовании Dahnhardt-Pfeiffer S. и соавт. [28] было продемонстрировано, что при использовании 0,1\% мази Протопик ${ }^{\circledR}$ и 0,1 \% крема мометазона фруроата у пациентов с АД в фразе обострения противовоспалительная терапия указанными препаратами через 10 дней приводила к увеличению содержания липидов в роговом слое в обеих группах, однако в группе, получавшей такролимус, оно было гораздо более выраженным, чем в группе, получавшей мометазона фруроат. По данным трансмиссионной электронной микроскопии, при использовании мометазона протяженность липидных мембран в межклеточном пространстве (МКП) возросла с $37 \pm 7$ до

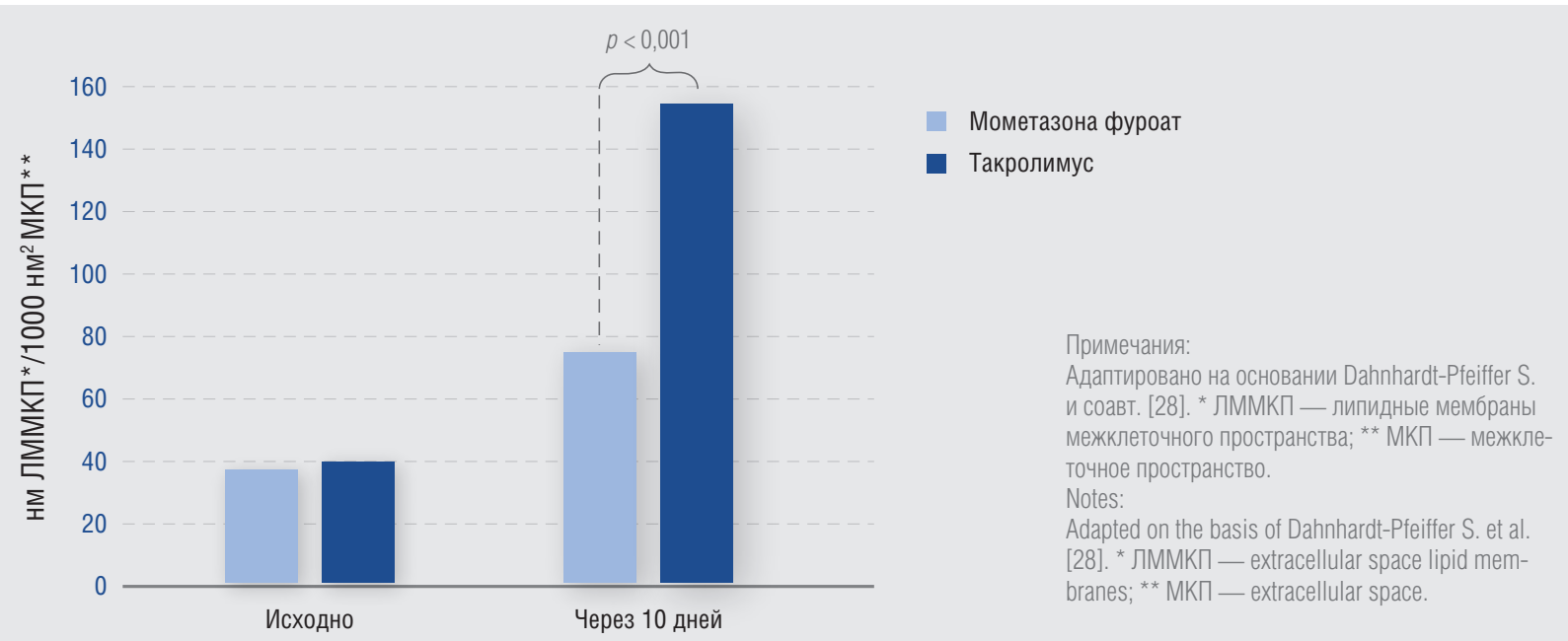

Рис. 4. Влияние терапии мометазона фуроатом и такролимусом (Протопик ${ }^{\circledR}$ )на протяженность липидных мембран в межклеточных пространствах рогового слоя пациентов с атопическим дерматитом

Fig. 4. Effect of therapy with mometasone furoate and tacrolimus (Protopic ${ }^{\circledR}$ ) on the length of lipid membranes in the intercellular spaces of the stratum corneum of patients with atopic dermatitis 


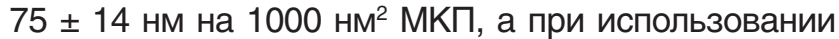
такролимуса - с $40 \pm 5$ до $155 \pm 2$ нм на 1000 нм² $^{2}$ МКП (см. рис. 4). При этом показатель увлажненности рогового слоя при использовании такролимуса Протопика значительно возрос, а при использовании мометазона не претерпел изменений.

Также представляет интерес исследование Lee S. E. и соавт. [28], в рамках которого изучалось влияние 10-дневной терапии 0,05 \% мазью клобетазола пропионата и 0,1 \% мазью такролимуса на плотные контакты эпидермоцитов мышиной кожи. При помощи конфокальной иммунофллуоресценции, вестерн-блоттинга и ПЦР в реальном времени оценивались структура и содержание ключевых белков плотных контактов - клаудинов 1 и 4 и окклюдина. Аппликации клобетазола пропионата приводили к выраженному нарушению структуры и снижению содержания всех трех белков, тогда как мазь такролимуса не оказывала влияния на клаудины 1 и 4 и приводила к снижению содержания окклюдина в меньшей степени, чем клобетазол. При этом применение клобетазола сопровождалось истончением эпидермиса, снижением плотности коллагена и повышением ТЭПВ, чего не наблюдалось при применении Протопика.

Сводные данные о влиянии терапии ТГКС и Протопика на различные параметры эпидермального барьера приводятся в таблице 3 .

Обращает на себя внимание, что появившийся в России генерический препарат мази такролимуса местного производителя может не обладать эквивалентным оригинатору положительным влиянием на морфофрунцциональные характеристики эпидермального барьера, поскольку в нем, в отличие от оригинального препарата (мази Протопик ${ }^{\circledR}$, присутствует водная фраза и, по этой при- чине, используется эмульгатор - эмульсионный воск. Эмульгаторы (поверхностно-активные вещества - ПАВ) представляют собой амфрифильную молекулу, имеющую гидрофильную и липофильную часть, за счет чего резко снижают поверхностное натяжение на границе раздела водной и липидной фраз; на этом принципе основывается действие различных моющих средств (мыла, стиральные порошки и т. д.), а также образование эмульсий в различных кремах. При этом действие эмульгаторов неизбирательно в отношении липидов рогового слоя эпидермиса, что приводит к нарушению его барьерных свойств [32-34].

С учетом данных исследований в реальной клинической практике необходимо использовать новый рациональный подход к наружной терапии атопического дерматита. Его задачей является выход из порочного круга, когда усугубление нарушения эпидермального барьера под действием стероидной терапии предрасполагает к постоянно рецидивирующему течению дерматоза. Поскольку мазь Протопик ${ }^{\circledR}$ по своей противовоспалительной активности не уступает сильным ТГКС, но в отличие от последних способствует восстановлению эпидермального барьера, с точки зрения клинического мышления выглядит оправданным перевод пациента с ТГКС на указанный препарат. Однако использованию мази такролимуса как препарата стартовой терапии при выраженном обострении АД препятствуют 2 фрактора. Первый - побочный эфффект в виде жжения, наблюдаемый в первые дни лечения такролимусом [35]. При выраженном воспалении данный побочный эфффект может усугубиться. Второй - лекарственной формой такролимуса является мазь, которая не является оптимальной при остром воспалении.

Таблица 3. Влияние терапии ТГКС и такролимусом (Протопик ${ }^{\circledR}$ ) на различные параметры эпидермального барьера (на основании источников [13, 15-17, 22-25, 28-31]) Table 3. Effect of TGCS and tacrolimus therapy (Protopic ${ }^{\circledR}$ ) on various parameters of the epidermal barrier (based on sources [13, 15-17, 22-25, 28-31])

\begin{tabular}{|c|c|c|c|}
\hline Свойство & Метод/параметр & TГKC & Такролимус \\
\hline Структура и толщина эпидермиса & $\mathrm{OKT}^{*}$ & отрицательно & Тенденция к положительно \\
\hline Структура и толщина эпидермиса & узи & отрицательно & положительно \\
\hline Структура и толщина эпидермиса & Синтез коллагена & отрицательно & положительно \\
\hline Целостность и когезия рогового слоя & Удаление липкой лентой/ТЭПВ & отрицательно & положительно \\
\hline Целостность и когезия рогового слоя & Белки плотных контактов & отрицательно & Нейтрально /отрицательно < ТГКС \\
\hline $\begin{array}{c}\text { Протеолитическая активность } \\
\text { в роговом слое }\end{array}$ & Активность протеаз & отрицательно & положительно \\
\hline Эфрфект на рН & рН-метрия & отрицательно & положительно \\
\hline Гидратация & Проводимость/корнеометрия & положительно & положительно \\
\hline Липидные пластины & Биопсия/ТЭМ ** & положительно & положительно > ТГКС \\
\hline Нарушение диффееренцировки & Филаггрин и Na-ПКК*** & отрицательно & Нейтрально/положительно \\
\hline Экспрессия антимикробных пептидов & 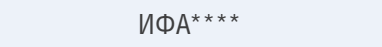 & отрицательно & Нейтрально/положительно \\
\hline
\end{tabular}

Примечание: * ОКТ — оптическая когерентная томография; ** ТЭМ — трансмиссионная электронная микроскопия; ***Na-ПКК — пирролидонкарбонат натрия; **** ИФА — иммуноферментный анализ.

Note: * OKT — optical coherence tomography; ${ }^{* *}$ ТЭМ — transmission electron microscopy; ${ }^{* \star *}$ Na-ПKК — sodium pyrrolidone carbonate; ${ }^{* * * \star}$ ИФA — enzyme immunoassay 


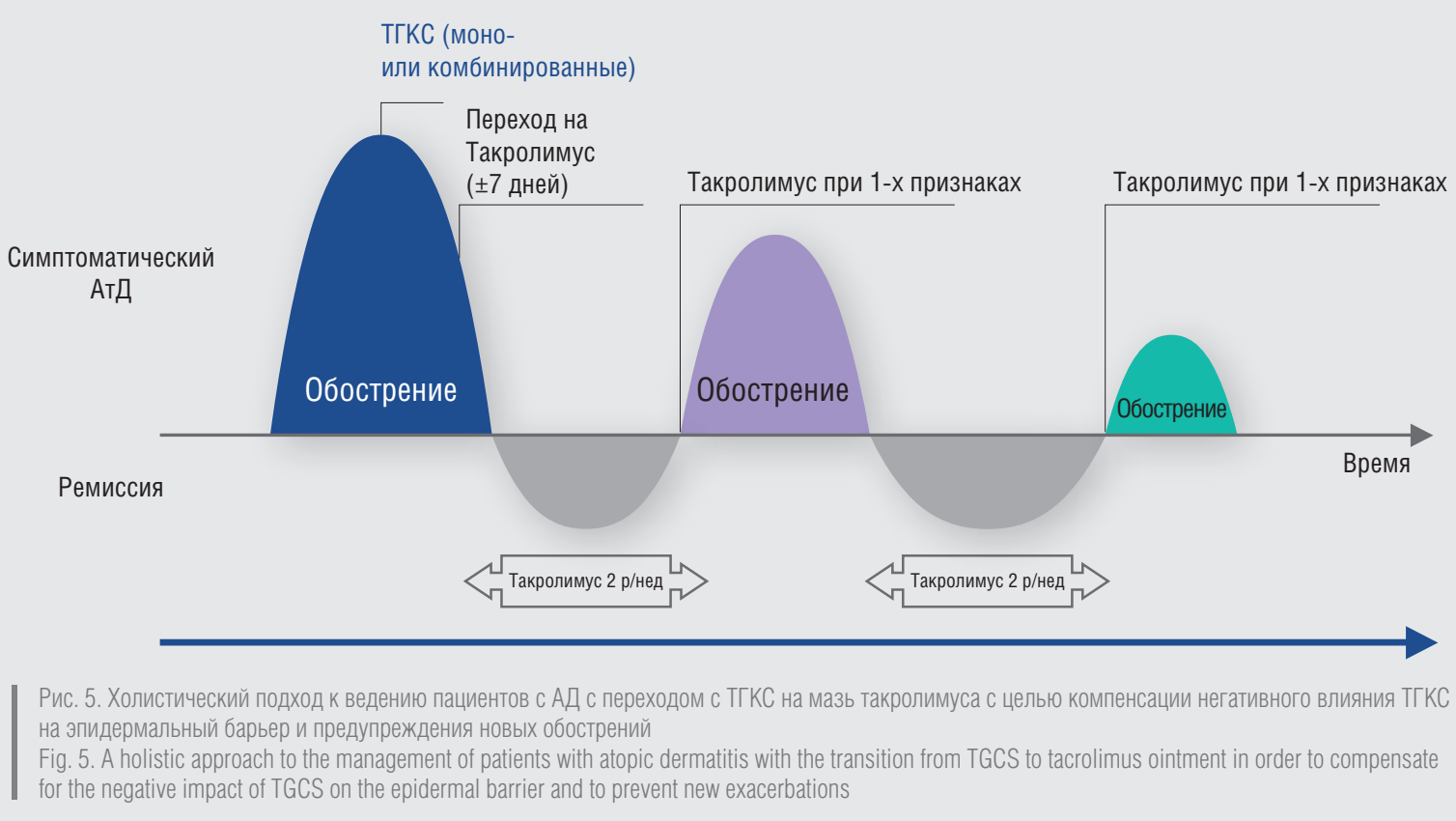

В связи с этим рациональной представляется схема, в рамках которой стартовой терапией является ТГКС (монокомпонентный либо, при наличии признаков вторичного инфицирования, комбинированный). Далее, по мере стихания островоспалительных симптомов (в среднем через \pm 7 дней), осуществляется перевод на мазь Протопик ${ }^{\circledR}$ и лечение продолжается до полного купирования обострения. Если АД имеет тяжелое течение с частотой обострений 4 и более в течение года, после достижения ремиссии рационально рекомендовать проактивную терапию мазью такролимуса (аппликации 2 раза в неделю) с целью пролонгации межрецидивного периода. При возникновении первых признаков обострения возможен перевод на ежедневное использование такролимуса. Разумеется, на всех этапах ведения пациента с АД показано применение эмолентов. Описанная схема лечения отражена на рис. 5.

\section{Заключение}

Таким образом, топические глюкокортикостероиды являются эффрективным противовоспалительным средством, но оказывают выраженное негативное влияние на морфоорункциональные характеристики эпидермального барьера. С учетом того что при АД нарушения эпидермального барьера играют важную роль в патогенезе, формируется порочный круг, когда усугубление нарушения эпидермального барьера на фроне стероидной терапии сокращает период ремиссии и влечет более частые и выраженные обострения АД. Оптимизация схемы лечения заключается в переводе пациента со стероидной терапии после достижения купирования острого воспаления на мазь такролимуса (Протопик $\left.{ }^{\circledR}\right)$, обладающую положительным влиянием на множество параметров эпидермального барьера - структуру, толщину и гидратацию рогового слоя, характеристики липидных пластин, протеазную активность, $\mathrm{pH}$, синтез антимикробных пептидов и т. д. Это позволит компенсировать негативное действие ТГКС, при этом обеспечивая противовоспалительную эффективность, не уступающую ТГКС III класса активности.

Указанная схема рационализирует подход к ведению пациентов с АД, позволяя взять его течение под контроль и снизить частоту и выраженность обострений.

В средне- и долгосрочной перспективе ожидается появление новых классов наружных противовоспалительных и иммуносупрессивных средств - например ингибиторов фоссфодиэстеразы-4 и Янус-киназы, которые также могут стать альтернативой ТГКС, но их влияние на эпидермальный барьер еще предстоит оценить.

\section{Литература/References}

1. Хлебникова А. Н., Петрунин Д. Д., Молочков А. В. Липиды человеческого эпидермиса (фундаментальные сведения и клиническая имплементация): Учебно-методическое пособие. М.: МОНИКИ, 2015; 71. [Khlebnikova A. N., Petrunin D. D., Molochkov A. V. Lipids of human epidermis. Fundamental data and clinical implementation: Study guide.
Moscow: MONIKI, 2015: 71. (In Russ.)]

2. Bieber T. Atopic Dermatitis. Ann Dermatol. 2010;22(2):125-137.

3. Dharmage S. C., Lowe A. J., Matheson M., Burgess J. A., AlIen K. J., Abramson M. J. Atopic dermatitis and the atopic march revisited. Allergy. 2014;69:17-27. 
4. Jungersted J. M., Scheer H., Mempel M., Baurecht H., Cifuentes L., Høgh J. K. et al. Stratum corneum lipids, skin barrier function and filaggrin mutations in patients with atopic eczema. Allergy. 2010;65:911-918.

5. Elias P. M., Steinhoff M. "Outside-to-Inside" (and Now Back to "Outside") Pathogenic Mechanisms in Atopic Dermatitis. J Invest Dermatol. 2008:128:1067-1070

6. Sugarman J. L., Fluhr J. W., Fowler A. J., Bruckner T., Diepgen T. L., Williams M. L. The objective severity assessment of atopic dermatitis score: an objective measure using permeability barrier function and stratum corneum hydration with computer-assisted estimates for extent of disease. Arch Dermatol. 2003:139:1417-1422.

7. Proksch E., Folster-Holst R., Jensen J. M. Skin barrier function, epidermal proliferation and differentiation in eczema. J Dermatol Sci. 2006:43:159-169.

8. Chamlin S. L., Kao J., Frieden I. J., Sheu M. Y., Fowler A. J., Fluhr J. W. et al. Ceramide-dominant barrier repair lipids alleviate childhood atopic dermatitis: changes in barrier function provide a sensitive indicator of disease activity. J Am Acad Dermatol. 2002:47:198-208.

9. Grimalt R., Mengeaud V., Cambazard F. The steroid-sparing effect of an emollient therapy in infants with atopic dermatitis: a randomized controlled study. Dermatology. 2007;214:61-67.

10. КР211. Клинические рекомендации - дерматит атопический. Российское общество дерматовенерологов и косметологов, 2016. [KP211 Clinical recommendations. Atopic dermatitis. Russian Society of Dermatologists and Cosmetologists, 2016. (In Russ.)]

11. Eichenfield L. F., Tom W. L., Berger T. G., Krol A., Paller A. S., Schwarzenberger Ketal. Guidelines of care for the management of atopic dermatitis: section 2. Management and treatment of atopic dermatitis with topical therapies. J Am Acad Dermatol. 2014;71(1):116-132.

12. Wollenberg A., Oranje A., Deleuran M., Simon D., Szalai Z., Kunz B. et al. ETFAD/EADV Eczema task force 2015 position paper on diagnosis and treatment of atopic dermatitis in adult and paediatric patients. J Eur Acad Dermatol Venereol. 2016;30(5):729-747.

13. Kao J. S., Fluhr J. W., Man M. Q., Fowler A. J., Hachem J. P., Crumrine D. et al. Short-term glucocorticoid treatment compromises both permeability barrier homeostasis and stratum corneum integrity: inhibition of epidermal lipid synthesis accounts for functional abnormalities. J Invest Dermatol. 2003;120(3):456-464.

14. Tadicherla S., Ross K., Shenefelt P. D., Fenske N. A. Topical corticosteroids in dermatology. J Drugs Dermatol. 2009:8(12):1093-1105.

15. Kolbe L., Kligman A. M., Schreiner V., Stoudemayer T. Corticosteroid-induced atrophy and barrier impairment measured by non-invasive methods in human skin. Skin Res Technol. 2001;7:73-77.

16. Sheu H. M., Lee J. Y., Chai C. Y., Kuo K. W. Depletion of stratum corneum intercellular lipid lamellae and barrier function abnormalities after long-term topical corticosteroids. Br J Dermatol. 1997;136(6):884-890.

17. Haapasaari K. M., Risteli J., Koivukangas V., Oikarinen A. Comparison of the effect of hydrocortisone, hydrocortisone-17-butyrate and betamethasone on collagen synthesis in human skin in vivo. Acta Derm Venereol. 1995;75(4):269-271.

18. Gebhardt C., Averbeck M., Diedenhofen N., Willenberg A., Anderegg U., Sleeman J. P., Simon J. C. Dermal hyaluronan is rapidly reduced by topical treatment with glucocorticoids. J Invest Dermatol. 2010;130(1):141-149.
19. Zhang W., Watson C. E., Liu C., Williams K. J., Werth V. P. Glucocorticoids induce a near-total suppression of hyaluronan synthase mRNA in dermal fibroblasts and in osteoblasts: a molecular mechanism contributing to organ atrophy. Biochem J. 2001;349(Pt 1):91-97.

20. Saarni H., Hopsu-Havu V. K. Inhibition of acid mucopolys accharide synthesis by hydrocortisone, hydrocortisone 17-butyrate and betamethasone 17-valerate. Br J Dermatol. 1977;97(5):505-507.

21. Carr W. W. Topical calcineurin inhibitors for atopic dermatitis: review and treatment recommendations. Pediatr Drugs. 2013:15:303-310.

22. Kyllonen H., Remitz A., Mandelin J. M., Elg P., Reitamo S. Effects of 1-year intermittent treatment with topical tacrolimus monotherapy on skin collagen synthesis in patients with atopic dermatitis. Br J Dermatol. 2004;150:1174-1181.

23. Бакулев А.Л., Кравченя С. С. Эфффективность топической терапии такролимусом при атопическом дерматите у взрослых. Вестник дерматологиии и венерологии. 2012;5:106-111. [Bakulev A. L., Kravchenya S. S. Efficacy of the topical therapy with tacrolimus in case of atopic dermatit is in adults. Vestn Dermatol Venerol. 2012;5:106-111. (In Russ.)]

24. Jiráková A., Rob F., Sečníková Z., Koblová K., Džambová M., Rajská L. Topical corticosteroids but not calcineurin inhibitors induced atrophy after four weeks. J Biol Regul Homeost Agents. 2015;29(3):701-706.

25. Chittock J., Brown K., Cork M. J., Danby S. G. Comparing the effect of a twice-weekly tacrolimus and betamethasone valerate dose on the subclinical epidermal barrier defect in atopic dermatitis. Acta Derm Venereol. 2015;95:653-658.

26. Hachem J. P., Man M. Q., Crumrine D., Uchida Y., Brown B. E., Rogiers $\mathrm{V}$. et al. Sustained serine proteases activity by prolonged increasein pH leads to degradation of lipid processing enzymes and profound alterations of barrier function and stratum corneum integrity. J Invest Dermatol. 2005;125:510-520.

27. Hachem J. P., Houben E., Crumrine D., Man M. Q., Schurer N., Roelandt $T$. et al. Serine protease signaling of epidermal permeability barrier homeostasis. J Invest Dermatol. 2006:126:2074-2086.

28. Dähnhardt-Pfeiffer S., Dähnhardt D., Buchner M., Walter K., Proksch E., Fölster-Holst R. Comparison of effects of tacrolimus ointment and mometasone furoate cream on the epidermal barrier of patients with atopic dermatitis. J Dtsch Dermatol Ges. 2013;11(5):437-443.

29. Lee S.E., Choi Y., Kim S. E., Noh E. B., Kim S. C. Differential effects of topical corticosteroid and calcineurin inhibitor on the epidermal tight junction. Exp Dermatol. 2013;22(1):59-61.

30. Reitamo S., Rissanen J., Remitz A., Granlund H., Erkko P., Elg P. et al. Tacrolimus ointment does not affect collagen synthesis: results of a single-center randomized trial. J Invest Dermatol. 1998;111:396-398.

31. Danby S. G., Chittock J., Brown K., Albenali L. H., Cork M. J. The effect of tacrolimus compared with betamethasone valerate on the skin barrier in volunteers with quiescent atopic dermatitis. Br J Dermatol. 2014;170(4):914-921.

32. Raab W., Kindl U., Daniels R. Pflegekosmetik. Ein Leitfaden. 3rd ed. Stuttgart: Wissenschaftliche Verlagsgesellschaft, 1999.

33. Wilhelm K. P., Cua A. B., Wolff H. H., Maibach H. I. Surfactant-induced stratum corneum hydration in vivo: prediction of the irritation potential of anionic surfactants. J Invest Dermatol. 1993;101(3):310-315.

34. Effendy I., Maibach H. I. Surfactants and experimental irritant contact dermatitis. Contact Dermatitis. 1995:33(4):217-225.

35. Mandelin J., Remitz A., Reitamo S. Effect of oral acetylsalicylic acid on burning caused by tacrolimus ointment in patients with atopic dermatitis. Arch Dermatol. 201:146(10):1178-1180

\section{Информация об авторах}

Лариса Сергеевна Круглова - д.м.Н., профессор, зав. кафредрой Центральной государственной медицинской академии Управления делами Президента Российской Федерации; e-mail: kruglovals@mail.ru

Дмитрий Дмитриевич Петрунин* - К.м.Н., менеджер по научно-медицинским вопросам 000 «ЛЕО Фармасьютикал Продактс»; е-таil: prof.preobrazhenskii@gmail.com

\section{Information about the authors}

Larisa S. Kruglova - Dr. Sci. (Med.), Prof., Departmental Head, Department of the Dermatovenereology and Cosmetology, Central State Medical Academy of Affairs Management Department of President of Russian Federation

Dmitry D. Petrunin* — Cand. Sci. (Med.), Manager for Scientific and Medical Issues, LEO Pharmaceutical Products, LLC 